\title{
GENE DOSAGE EFFECTS FOR COAGULATION FACTORS XII (F12) AND XIII SUBUNIT A (F13A) IN A CASE WITH PARTIAL MONOSOMY 6p RESULTING FROM A MATERNAL PERICENTRIC INVERSION OF CHROMOSOME 6
}

\author{
Kouji Narahara, ${ }^{1}$ Yoshihito Seno, ${ }^{2}$ Youhei Nishibayashi, ${ }^{2}$ \\ Kei Hiramoto, ${ }^{1}$ Hiroshi Nanba, ${ }^{1}$ Kiyoshi KikKawa, ${ }^{1}$ \\ and Hiroshi Kiмото ${ }^{1}$ \\ ${ }^{1}$ Department of Pediatrics, Okayama University School of Medicine, \\ Okayama 700, Japan \\ ${ }^{2}$ Department of Pediatrics, Matsuyama Red Cross Hospital, \\ Matsuyama 790, Japan
}

\begin{abstract}
Summary Genes encoding blood coagulation factors XII (F12) and XIII subunit A (F13A) have been shown to be localized in the distal 6p region. We studied gene dosage effects for F12 and F13A in a female case with a duplication-deficiency (partial monosomy for $6 \mathrm{p} 2307 \rightarrow$ pter and trisomy for $6 \mathrm{q} 25.1 \rightarrow \mathrm{qter}$ ) due to a maternal inversion of chromosome 6 . Plasma levels of factor XII were reduced in the patient $(46 \%)$ and her mother $(42 \%)$, while that in her father $(56 \%)$ was within the normal range. On the other hand, plasma levels of factor XIII were normal in the three individuals and the phenotype of factor XIII subunit A was type 1 in all the three. The low factor XII values in the patient and the mother can be best explained by a duplex gene dosage for F12 but with the involvement of a variant gene which results in F12 with a low activity and exists in the two individuals. These results suggested that the loci encoding F12 and F13A can be excluded from the region $6 \mathrm{p} 2307 \rightarrow$ pter.
\end{abstract}

\section{INTRODUCTION}

Blood clotting factor XII (FXII) is activated by contact with foreign surfaces, and initiates the intrinsic pathway of coagulation. The localization of the gene encoding this protein (F12) in the distal $6 \mathrm{p}$ region has first been indicated by de Grouchy et al. (1968) and been confirmed by Pearson et al. (1982). In human gene mapping 8 (HGM 8), the locus is assigned to $6 \mathrm{p} 23$. The activated form of factor XIII (FXIII) acts in the common pathway of coagulation where it stabilizes covalent

Received July 28, 1987; Accepted September 14, 1987 
bonds within fibrin strands. This protein consists of two pairs of subunits, i.e., two alpha chains (FXIIIA) and two beta chains (FXIIIB). The detection of genetic polymorphism for FXIIIA (Board, 1979) has facilitated linkage studies with other various genetic markers, and the close linkage between F13A and HLA has been established (Eiberg et al., 1984; Olaisen et al., 1985). In HGM 8, its recombination. fraction in males $(\theta)$ is reported to be 0.19. Although the loci, F12 and F13A, are assumed to form a coagulation gene cluster in the $6 \mathrm{p} 23$ region, their detailed localization remains to be determined at subband levels. We studied gene dosage effects for F12 and F13A in a case with a duplication-deficiency (trisomy for $6 \mathrm{q} 25.1$ $\rightarrow$ qter and monosomy for $6 \mathrm{p} 2307 \rightarrow$ pter) resulting from a maternal pericentric inversion of chromosome 6 . The results excluded the two loci from the region $6 \mathrm{p} 2307 \rightarrow$ pter.

\section{MATERIAL AND METHOD}

Case report. The proband, a female infant, was born after an uneventful 40 weeks' gestation to unrelated parents (both 29 years of age). An elder sibling was healthy. There was no family history for mental retardation or multiple congenital anomalies. The birth weight was $2,120 \mathrm{~g}$, and the length $45.2 \mathrm{~cm}$. Immediately after birth, the infant was found to have brachymicrocephaly with high forehead, hypertelorism, antimongoloid eye slantings, exophthalmos, flat nasal bridge, small anteverted nose, long philtrum, full cheeks, low-set and malformed ears with folded helices and prominent antihelices, short neck with anterior as well as posterior webbings, heart murmurs (VSD and PH), pigeon breast, left-sided clubfoot and flexion contractures of all fingers. The subsequent clinical course was marked by episodes of cardiac failure, which were treated with digitalis and diuretics. The infant fed poorly and underwent permanent gavage feedings. Her psychomotor and somatic developments were grossly retarded.

Cytogenetic and genetic marker studies. Chromosome analysis was carried out on peripheral blood lymphocyte cultures from the patient, her parents and sibling. Prophasic or prometaphasic cells were collected according to the method of Ikeuchi and Sasaki (1979), and chromosome preparations were processed by GTG banding.

HLA-A, -B, -C, and -DR typing of peripheral blood lymphocytes was based on a standard dye-exclusion microcytotoxicity test. Glyoxalase of red blood cells (GLO1) was separated on a starch gel, using the method of Parr et al. (1977). FXII and FXIII were assayed by the method of Sirridge and Shanon (1983) and the caseindansyl cadaverine method (Iatro-FL FXIII Kit, Iatron Laboratories, Inc.), respectively. Phenotypes of FXIIIA were determined, using agarose gel electrophoresis as described by Nishigaki et al. (1981). 


\section{RESULTS}

\section{Cytogenetic studies}

Banding analysis of the patient showed that the distal portion of the short arm of one chromosome 6 was stained differently from the equivalent portion of the normal homologue. Her mother was found to have a pericentric inversion of chromosome 6. Analysis of prophasic cells at the level of 850 bands per haploid set revealed the locations of breakpoints at 6p2307 and 6q25.1 (Fig. 1a). A meiotic crossing-over between the inverted and normal chromosomes 6 of the mother appeared to have yielded the recombinant chromosome 6 seen in the patient, where the segment $6 \mathrm{q} 25.1 \rightarrow$ qter was duplicated and the segment $6 \mathrm{p} 2307 \rightarrow$ pter was deleted (Fig. 1b). The patient's karyotype was therefore 46,XX,rec(6), dup q,del p,inv(6) (p2307q25.1)mat. Her father and sibling had a normal G-banded karyotype.

\section{Genetic marker studies}

Table 1 showed the results of genetic marker studies. None of HLA-A, -B, -C or -DR loci were deleted in the patient. Phenotypes of GLO1 from the patient and her parents were all type 2 . The levels of FXII were markedly reduced in both the patient $(46 \%)$ and the mother $(42 \%)$, while that was within the normal range in

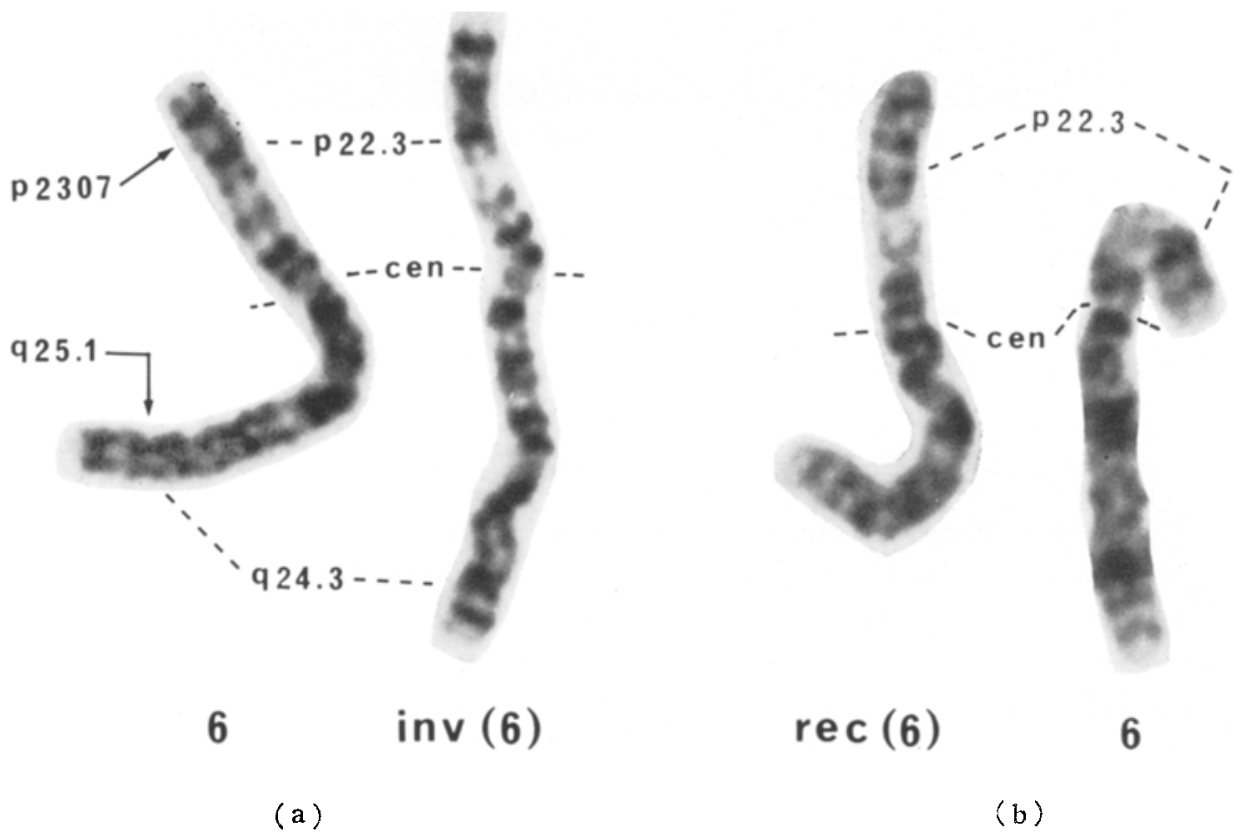

Fig. 1. Partial G-banded karyotypes of the patient (b) and the mother (a). Arrows indicate breakpoints of the inversion. 
Table 1. Results of gene marker studies.

\begin{tabular}{lccc} 
& \multicolumn{1}{c}{ Patient } & Father & Mother \\
\hline HLA & A2,A26,BW35,B(-), & A26,AW24,BW62,B(- $),$ & A2,AW24,BW35,BW51, \\
& CW3,CW7,DR1,DR4 & CW3,CW7,DR1,DR1 & CW3,C(-),DR4,DRW8 \\
GLO1 & Type 2 & Type 2 & Type 2 \\
$\begin{array}{l}\text { FXII } \\
\text { (normal, 50-150\%) }\end{array}$ & $46 \% \%^{\mathrm{a}}$ & $56 \%^{\mathrm{a}}$ & $42 \% \%^{\mathrm{a}}$ \\
$\begin{array}{l}\text { FXIII } \\
\text { (normal, 50-150\%) }\end{array}$ & $80 \%$ & $94 \%$ & $81 \%$ \\
FXIIIA & Type 1 & Type 1 & Type 1 \\
\hline
\end{tabular}

a Means of two separate measurements.

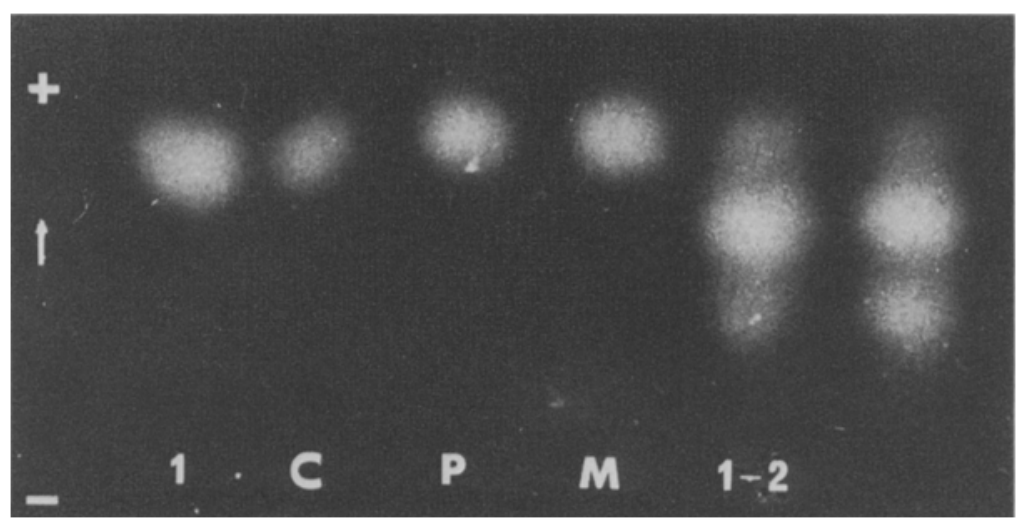

Fig. 2. Agarose gel electrophoresis of factor XIIIA from the patient (C), father (P) and mother (M).

the father $(56 \%)$. In all the three, on the other hand, levels of FXIII were normal. Phenotypes of FXIIIA were all type 1 (Fig. 2).

\section{DISCUSSION}

Figure 3 summarizes physical and genetic mapping data for chromosome 6 loci presented in HGM 8. The shortest region of overlapping (SRO) for F12, HLA, GLO1 and PGM3 has been assigned to 6p23, 6p21.3, 6p21.31 $\rightarrow$ p21.2 and $6 \mathrm{q} 12$, respectively. On the basis of male recombination fractions, the gene order pter-ME2 (mitochondrial malic enzyme)-F13A-HLA-GLO1-PGM3 has been proposed. The genetic distance between the loci for ME2 and F13A is found to be 10 centimorgan (cM), that for F13A and HLA $19 \mathrm{cM}$, that for HLA and GLO1 $4 \mathrm{cM}$, and that for GLO1 and PGM3 $15 \mathrm{cM}$. As regards ME2 and F13A, however, there has been no evidence for physical assignment nor deletion mapping to the distal $6 \mathrm{p}$ region. 


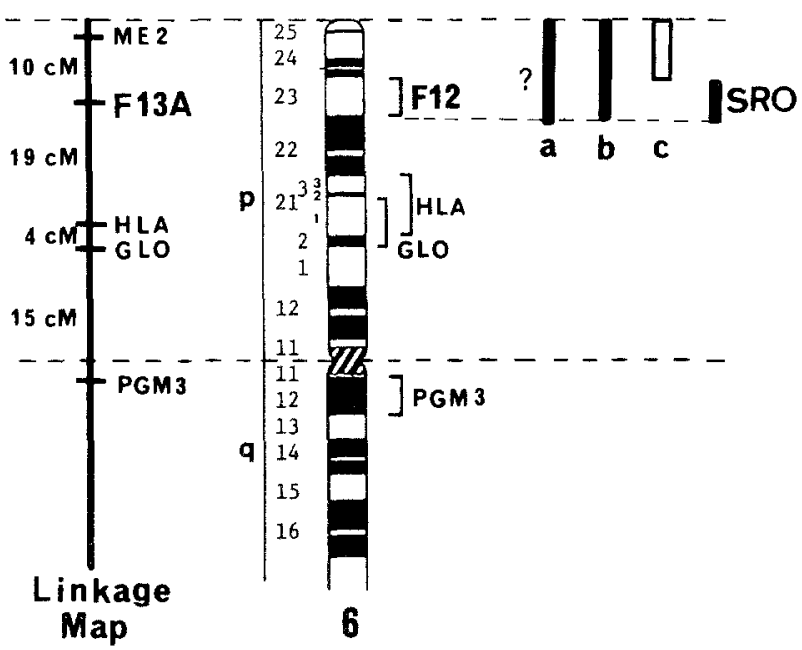

Fig. 3. Physical and genetic mapping data for chromosome 6 loci (Lam and Olaisen, 1985). As regards F12, a solid bar represents a segment to which the locus is assigned, and an open bar a segment from which the locus is excluded: a, de Grouchy et al. (1968), "?"' indicates undescribed breakpoints; b, Pearson et al. (1982); and c, Niebuhr et al. (1985).

The present study has shown markedly reduced levels of FXII not only in the patient with a duplication-deficiency (monosomy for 6 p2307 $\rightarrow$ pter and trisomy for $6 \mathrm{q} 25.1 \rightarrow \mathrm{qter})$ but also in the mother with a pericentric inversion of chromosome 6. This confounding result can be explained in three ways. First, the locus, encoding F12 lies within the region $6 \mathrm{p} 2307 \rightarrow \mathrm{p} 2400$, and the patient, a duplicationdeficiency recombinant, is hemizygous for this locus. The involvement of a variant gene which results in F12 with a low activity and exists in the mother would be a prerequisite for this supposition. Second, the locus is located just on the breakpoint of the inversion, $6 \mathrm{p} 2307$. As a result of a gene disruption or a submicroscopic deletion of the locus for F12 during the process of the inversion, both the patient and the mother would become hemizygous for F12. Third, the locus exists proximal to the breakpoint. In this case, the patient should be heterozygous for a common F12 allele and a variant allele which results in F12 with a low activity and is inherited from the mother. In the former two explanations the FXII level of the patient depends only on that of the father, while in the third explanation the level is influenced by that of the mother as well as the father. The similarity of FXII level of the patient to the mean parental value is most in accordance with the third explanation, suggesting the exclusion of the F12 locus from the region 6 p2307 $\rightarrow$ pter.

Niebuhr et al. (1985) have described a normal F13A level in a case with partial trisomy $2 \mathrm{p}(\mathrm{p} 24 \rightarrow \mathrm{pter})$ and partial monosomy $6 \mathrm{p}(\mathrm{p} 24 \rightarrow \mathrm{pter})$ derived from the paternal balanced translocation, $\mathrm{t}(2 ; 6)(\mathrm{p} 24 ; \mathrm{p} 24)$. Our study has also showed the 
normal F13A level in the patient with monosomy for $6 \mathrm{p} 2307 \rightarrow$ pter. Although the two studies failed to substantiate the localization of F13A in the distal $6 \mathrm{p}$ region by deletion mapping, in view of the genetic distance between the loci for F13A and HLA (its $\mathrm{SRO}=6 \mathrm{p} 21.3$ ) in males whose chiasma map distance is reported to be $55 \mathrm{cM}$ of length (Morton et al., 1982), we would like to assume that the loci encoding F12 and F13A may form a coagulation factor gene cluster in the region $6 \mathrm{p} 2300 \rightarrow$ p2307 as do the loci encoding F7 and F10 in the 13q34 region (Pfeiffer et al., 1982). The confirmation of this hypothesis will have to await gene dosage studies in further cases with partial monosomy $6 \mathrm{p}$ or in situ hybridization studies using a complementary DNA for F12 or F13A.

\section{REFERENCES}

Board, P.S. 1979. Genetic polymorphism of the A subunit of human coagulation factor XIII. Am. J. Hum. Genet. 31 : 116-124.

de Grouchy, J., Veslot, J., Bonnette, J., and Roidot, M. 1968. A case of ?6p-chromosomal aberration. Am. J. Dis. Child. 115: 93-99.

Eiberg, H., Nielsen, L.S., and Mohr, J. 1984. Confirmation of F13A assignment and sequence information concerning F13A-HLA-GLO. Clin. Genet. 26: 385-388.

Ikeuchi, T. and Sasaki, M. 1979. Accumulation of early mitotic cells in ethidium bromide-treated human lymphocytes cultures. Proc. Jpn. Acad. 55: 15-18.

Lam, L.U. and Olaisen, B. 1985. Report of the committee on the genetic constitution of chromosomes 5 and 6 (HGM 8). Cytogenet. Cell Genet. 40:128-155.

Morton, N.E., Lindsten, J., Iselius, L., and Yee, S. 1982. Data and theory for a revised chiasma map in man. Hum. Genet. 62: 266-270.

Niebuhr, E., Eiberg, H., and Schousboe, I. 1985. Localization of human F12, F13A and ACP1 (abstract). Cytogenet. Cell Genet. 40: 714.

Nishigaki, T., Omoto, K., and Juji, T. 1981. Genetic polymorphism of the A subunit of human coagulation factor XIII in Japanese. Jpn. J. Human Genet. 26: 237-241.

Olaisen, B., Gedde-Dahl, T., Jr., Teisberg, P., Thorsby, E., Siverts, A., Jonassen, R., and Wilhelmy, M.C. 1985. A. structural locus for coagulation factor XIIIA (F13A) is located distal to the HLA region on chromosome 6p in man. Am. J. Hum. Genet. 37: 215-220.

Parr, C.W., Bagster, I.A., and Welch, S.G. 1977. Human red cell glyoxalase I polymorphism. Biochem. Genet. 15: 109-113.

Pearson, P.L., van der Kamp, J., and Veldtkamp, J. 1982. Reduced Hageman factor level in a 6p - patient (abstract). Cytogenet. Cell Genet. 32: 309.

Pfeiffer, R.A., Ott, R., Gilzenkrantz, S., and Alexandre, P. 1982. Deficiency of coagulation factors VII and $X$ associated with deletion of a chromosome 13(q34). Evidence from two cases with 46,XY,t(13;Y) (q34;q11). Hum. Genet. 62: 358-360.

Sirridge, M.S. and Shanon, R. 1983. Laboratory Evaluation of Hemostasis and Thrombosis, 3rd Ed., Lea and Febiger, Philadelphia, pp. 130-133. 